\title{
Climate Adaptive Skins: towards the new energy-efficient façade
}

\author{
B. L. H. Hasselaar \\ Department of Building Technology, Chair of Building Physics, \\ Delft University of Technology, The Netherlands
}

\begin{abstract}
Façades perform many different functions and are made up of many different parts and materials. Mike Davies was the first to describe a façade made up of one layer that was still able to cater to different functions. In an effort to realise this 'polyvalent façade' as described by Davies, multiple features have since been integrated into the façade, each addressing a specific need. Building skins that are considered to be at the forefront of modern façade technology however are basically all variations on the same theme, hardly doing anything but reacting to the current environmental conditions and the situation created by the façade itself. As such, they are ad hoc devices, able to adjust to a specific circumstance at that specific time, but unable to save, store or prepare for another circumstance. The outdoor climate changes through time and season, alternately supplying energy to and drawing energy from the building skin. Most modern façades have no means to buffer between the two, other than trapping air in a double skin façade to use as a warm blanket in winter. Although some buildings utilise thermal mass in floors/ceilings and aquifers to store heat/cold between day/night and seasons, these are technologies that function independently from the building skin, aiding the building installations. Climate Adaptive Skins (CAS) should differ from 'conventional' façades in a way that they are able to adjust their characteristics to and mediate between the changing environments. By doing so they are able to provide a comfortable indoor temperature, lighting level and air quality (parameters influencing energy consumption) without excess use of energy.
\end{abstract}

Keywords: façade, adaptive, climate control, comfort, low energy, polyvalent. 


\section{Introduction}

Historically, the first reason why people sought shelter in caves was protection from the elements. Later, shelters were developed that were more elaborate and able to address people's needs better. Since the industrial revolution this process has taken a huge flight as requirements became more stringent (especially for working/office environments) and technologies for more complicated building skins became available.

The annualised cost for the construction of an (office) building is stated to be between 5 and $10 \%$ of the total annual cost for an enterprise over 20 years, while employee cost varies between 75 and $92 \%$ of total expenditure [2,3]. Judging from the fact that many people are dissatisfied to some extend with their working environment/climate and that part of that dissatisfaction is building related, a better building performance is likely to reduce health complaints of the users, increasing working efficiency. Paying more attention to the performance of the (new) façade is therefore likely to be profitable.

This paper will describe the first steps in the $\mathrm{PhD}$ research towards a new energy-efficient adaptable façade concept. The research will focus mainly on climatic conditions similar to those in The Netherlands, as that is where the research is being conducted.

\section{Functions of a façade}

To provide optimal comfort to users, it is difficult to cater for every physical aspect as one might contradict another: requirements for acoustic quality differ from those for thermal insulation, which in turn differ from the requirements for daylight admittance. However, there are some basic functions that every building skin needs to encompass, such as being waterproof, providing shelter from wind and thermal insulation as well as being structurally sound. Regarding the office environment, a set of additional requirements of the façade can be formulated, to provide the user with an optimal working environment: thermal comfort, indoor air quality, agreeable lighting level and an acoustic comfortable environment.

\section{Current situation}

Buildings and climate control systems are normally designed separately rather than integrated, with the result that substantial Heating, Ventilation and AirConditioning (HVAC) installations are needed to create an agreeable indoor environment. However, this does not automatically result in the most energy efficient design, nor does it mean that users will perceive the indoor climate as comfortable. The latest insights indicate that occupants who have greater access to controls (e.g. those close to a window) report less discomfort than those who have less access (e.g. away from the window) [4], with current research into Adaptive Temperature Limits indicating that buildings that are (partly) naturally ventilated and have a certain level of user control allow higher indoor temperatures [5]. 


\subsection{Definitions}

This research focussed on the development of new concepts for energy efficient façades. As such, it is important to define some of the terms that are used, to avoid confusion. Some of the terms defined however, are used in the same context by people in the building industry. To avoid confusion, such terms relevant to this research are also defined:

Façade: the front or face of a building.

Skin: the enclosure of a space, the separator of interior and exterior. The skin of a building can be foundation, façade or roof, depending on the context.

Comfort: is a term literally meaning 'state of physical ease and freedom from pain or constraint' [6]. The conditions that make a person feel comfortable however are not unambiguous: they are dependent of e.g. psychological, and physiological factors and can differ from person to person.

Adaptive: 'become adjusted to new conditions'. This definition immediately introduces a second, related term: adjusted, which has two useful definitions: 'alter slightly as to achieve the desired result', and 'become used to a new situation'. Both meanings are of importance to this research, although adaptive and adjustable have two different annotations: adaptive means the ability to adjust and adapt to changing circumstances by itself. Adjustable, similar to adaptable means the ability to adjust by external interference, such as by human hand.

Responsive: meaning 'responding readily and positively' with respond meaning in this context: 'do something as a reaction' [6]. With respect to façades, the difference between adaptive and responsive is that responsive does not actually mean the adjustment of specific characteristics to the environment, but merely responding to a change in climate by, for example, lowering blinds or opening windows.

Intelligent: literally meaning the 'ability to vary its state or action in response to varying situations and past experience'. This implies the presence of a computer or a central control centre, since past experiences are used to determine the action to be undertaken next. Adjustment of façade components takes place after a signal from a sensor that registers a change of circumstances. In order to function properly, they need to be connected to an electricity source.

Smart, or 'having a quick intelligence' [6] is often used as a synonym to intelligent, but has a different meaning in the view of the author. A smart material does not necessarily need electronics to adjust its characteristics and applies mainly to materials, not as much to façades or components as a whole. Materials that adjust their characteristics under the direct influence of the environment are smart materials, such as photochromic glass that changes colour when exposed to (bright) light.

Passive, meaning accepting or allowing what happens or what others do, without active response or resistance. Also: containing no source of energy or electromotive force. Applied to a façade, this means that passive components do not react mechanically to a change in circumstances. 
Active, as apposed to passive, responds to its environment. The term itself has multiple meanings according [6], but in this context meaning working/operative and/or: capable of automatic change in response to input or feedback. The input comes from a computer or other kind of control centre (also see 'intelligent'), and enables the active device to change its orientation, shape and/or other feature that enables it to influence the interaction between indoor and outdoor climate.

\subsection{Features of modern façades}

Many of the buildings that are considered to be energy efficient, use the building itself, not the façade, as part of their energy strategy. There are few façades that incorporate passive or smart technologies to aid the building installations in creating a comfortable indoor climate, apart from shading technologies through blinds or louvers and operable windows for ventilation. Widely used techniques are the use of thermal mass of the floors in combination with night flushing as a passive means for cooling, boreholes in combination with heat pumps for either heating or cooling, and atria to preheat ventilation air before it is distributed to occupied zones. Although these are all more or less passive means of climate control, employing natural principles to adjust the indoor climate, they are technologies that operate practically independent of the façade.

\subsubsection{View openings}

Many façades can be divided into two parts: a transparent part used for daylight and view, and a non-transparent part, used for insulation, privacy and structural purposes. Each part has its own characteristics, although often they are not fully separated and share certain building aspects, such as ventilation.

Case study research [7-9] has shown that almost any modern façade that claims to be 'adaptable', 'intelligent' or 'responsive' can be deduced to one of five different types of solar control devices [10], as demonstrated in figure 1.

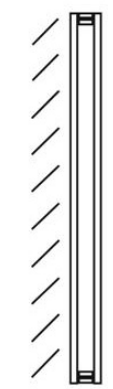

external

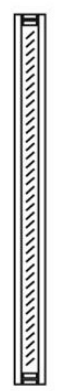

integrated

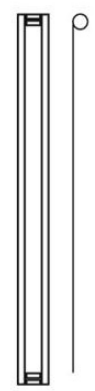

internal

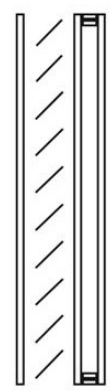

double skin

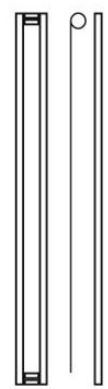

ventilated cavity

Figure 1: Schematic cross-section of view openings. 
External solar control devices reflect and emit the heat absorbed from solar radiation outside the building itself, reducing the need for cooling in summer. The outdoor elements are exposed to the elements resulting in higher costs for maintenance and cleaning. External devices can be fixed (projecting roofs or building sections, awnings, brise-soleils, fixed-angle louver shading) or movable (fabric blinds or screens, slatted or metal louver blinds). Less common are sliding façade units such as panels, screening grids and light-deflecting elements.

Integrated solar control devices are relatively uncommon. Because the devices are contained in an enclosed space, cleaning costs are relatively low. Maintenance costs however can be much higher, especially in cases where the electric motors are also incorporated in the cavity between the panes. An alternative is presented by systems that make use of a magnetic control placed outside the insulating glass.

Internal solar control devices are less effective, as the light passing through glass is transformed into heat by the shading device, which is trapped by the glass and emitted into the room. This effect can to some extend be reduced by drawing off the warm air above these devices. Cleaning and maintaining these devices is considerably easier than exterior and integrated ones, as they can easily be reached. Readily available systems include Venetian blinds and textile materials such as vertical blinds, roller blinds or fabric screens.

Double skin façades have an extra (usually) glass sheet on the outside of a building, posing in front of the actual building façade. The cavity in between the two façades contains some sort of 'intermediate' climate, hence the term 'double skin'. Solar control devices are placed in the cavity between these two skins, which protects them from the influences of weather and air pollution. Heat absorbed by the solar shading is re-radiated and emitted into the intermediate cavity, creating a natural stack effect which causes the air to rise, removing additional heat with the upward flow.

Ventilated cavity façades have an additional single glass sheet on the inside of an interior solar control device. The cavity thus created is mechanically ventilated. Lower pressure in the cavity draws part of the exhaust air from the room into this space where the air warms up, taking most of the heat from the solar control devices, and is then drawn off. The air is extracted on each floor separately, either flowing upwards or downwards in the cavity. For reasons of optimal airflow, horizontal blinds are less suitable. Because temperature differences between the room and the glass surface are small, thermal comfort conditions in the office space near the windows improve.

\subsubsection{Combined façades}

The classification of façades as described above is mainly concentrated on transparent parts, used for light admittance and view. The non-transparent parts, usually at parapets and ceilings, generally have a very different appearance and function, concealing many of the building services and consisting of very different materials and constructions. As such, these parts can be divided into two variants: cold cavity façades and warm cavity façades [8]: 


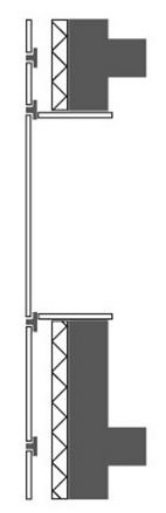

Cold cavity

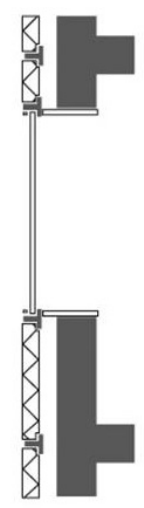

Warm cavity

Figure 2: Schematic cross-section of the façade.

Cold cavity façades function as an aesthetic raincoat. The skin gets its strength and rigidity mostly from the underlying construction. The cavity is ventilated with outdoor air; insulation is placed on the outside of the inner leaf. Advantages of this type of facades are the accessibility of the construction and the ease of replacing or altering the façade, giving great flexibility in terms of choice of material for the outer skin. A disadvantage is that the system is relatively unsuitable for building with large façade components.

Warm cavity façades have a cavity separated from outdoor air. The parapet panels contain insulation and are placed at cavity distance from the load bearing structure, making it a complete façade in front of the load bearing façade (see figure 2). This type of façade is suitable for use as component and super component (unit), however, it is also associated with high building costs, limited choice of materials for the non-transparent parts and less accessible construction with inflexibility in case of replacing or altering (parts of) the façade.

\subsection{Limitations of current façades}

These days, most buildings are insulated to such an extent that, in summer when outdoor temperatures are relatively high, buildings tend to overheat due to the higher sum of internal heat production by sources such as computers, lighting and people themselves and solar gain through windows than, the heat loss through the building skin. Additional insulation is not likely to reduce the building energy consumption but on the contrary causes an increase in energy consumption, as heat inside the building is retained longer; extending the period in which cooling is needed to provide a comfortable indoor climate.

In the Netherlands, the average temperature throughout the year is just under $10^{\circ} \mathrm{C}$, well below a comfortable indoor temperature. Even in summer, the average daytime outdoor temperature barely reaches 19 degrees Celsius. Based solely on these numbers one would expect that additional heating is needed throughout the year. However, this does not account for solar radiation and 
internal heat production through the use of appliances (e.g. $100 \mathrm{~W}$ per computer [11]), or simply the presence of people: one person at rest, standing produces approximately $125 \mathrm{~W}$ of metabolic heat [12].

As figure 3 shows, the maximum temperature difference during a 24-hour day is the greatest in summer, averaging up to $11^{\circ} \mathrm{C}$, as opposed to about $5^{\circ} \mathrm{C}$ in winter. This means that the possibility to utilise differences in temperature in the outdoor climate on average is better in summer, which is also when the biggest chance of overheating of the indoor climate occurs. The mean temperature difference between summer and winter is $14,5^{\circ} \mathrm{C}$. If it would be possible to store thermal energy for several months, it would be possible to use summer warmth to heat in winter and cold from winter to cool in summer. It is questionable however, whether this is feasible or attainable on façade level.

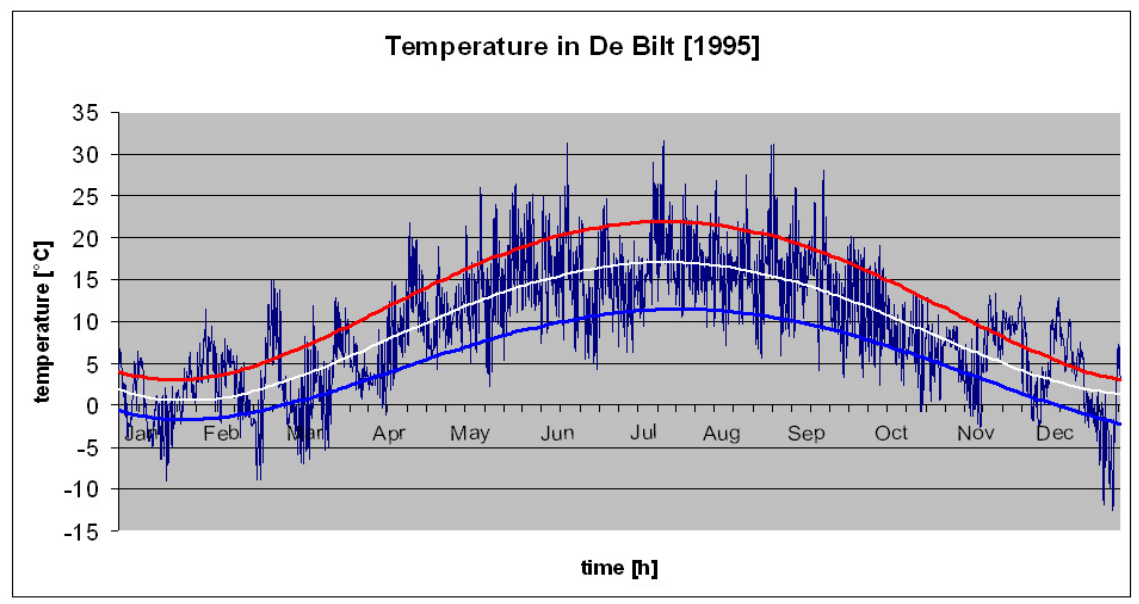

Figure 3: Temperatures during a test reference year.

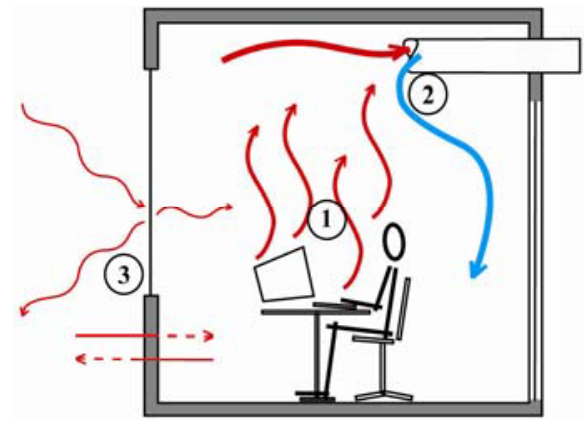

Figure 4: Factors that influence the indoor climate.

If one would be able to isolate the HVAC and the interaction with the outdoor climate, an office environment would function as a net heat producer (see (1) in figure 4): Omitting the influence of the outdoor climate, the building's HVAC 
installations are needed to compensate for the internal heat production, taking away excess heat and providing fresh air (2). Basically, these installations produce cool air or water for the indoor environment by drawing heat from it at one location, shedding the heat to the outdoor environment, and transport the cool air or water to another location. In this case, the outdoor environment acts only as a big waste bin for the excess heat. If we would replace the centralised HVAC installations with a small installation for every office room, the devices would be located at each room's façade to be able to shed unwanted heat to the outside. The situation would be slightly more complicated, but essentially the same if we included the influence the outdoor climate has on the indoor climate (3). This influence sometimes calls for additional heating or cooling, or additional lighting. Depending on the climate, the weather and time of year and/or day, the outdoor climate can be used as a source, or should be rejected because it puts too much load onto the indoor environment.

Current façades and HVAC installations are mostly separate entities, influencing each other, but rarely integrated. If a façade would be able to mediate between the indoor and outdoor climate, regulating the exchange of fresh air and heat/cold between the two, and providing additional heating/cooling when desired, the need for additional HVAC installations would be abolished (at least, for the zone within reach of the façade). Although there are some examples of buildings where HVAC installations are located near or in the façade, they are not truly integrated. The integration of HVAC installations within the façade could stimulate integration of different components catering different functions, thus effectively reducing energy consumption needed for the acclimatisation of the indoor environment. By utilising the changes in climate through time and season, the required energy for climate control could potentially be reduced even further.

The principles behind the working of a façade can be explained using terms as described in paragraph 3.1, indicating the amount and type of technology used. The increasing availability of computing power and information through sensors and even the internet makes that many modern buildings utilise intricate, centralised building management systems (BMS) to be optimally able to respond to the outdoor climate. The downside to these technologies is that if (part of) the building management system malfunctions, potentially the whole building climate system is no longer operational, leading to uncomfortable and/or energy consuming situations. Passive technologies are unlikely to fail because they do not actively perform an action but merely influence their environment by their physical characteristics. For that reason however, their application is somewhat limited.

\section{Outlook}

The intention of this research is to develop principles and concepts for a new type of façades that utilises mostly passive technologies but is still able to provide a comfortable indoor climate throughout the year. By integrating climate controlling elements into the façade, the need for additional, centralised building 
services is reduced, reducing the overall consumption of energy for HVAC installations. Because the façade operates using mostly passive technologies, it is less dependent of input (being electricity, thermal energy or data) from the building it is attached to. The independent operation of the façade makes application to both new and renovated buildings easier. The absence of a centralised control centre and many controlling parts reduces maintenance and increases the robustness of the system. Its independence of any external input own enables continuing functionality, even in case of power failure.

An example of the Climate Adaptive Skin (CAS) can be seen in figure 5: an outer sheet of thermotropic glass (1) admits or rejects sunlight, depending on temperature. A valve (2) determines whether ventilation air is pre-heated in the cavity behind the outer sheet (left), or drawn directly from the outside (right), after which the air is brought to temperature by Phase Change Material (PCM) plates (4). A fan (3) pressurises the cavity between (5) and (7), after which the conditioned air is distributed through the micro-porous inner leaf (5). A manually operable window can provide additional ventilation. Exhaust air is drawn from the space above the suspended ceiling.
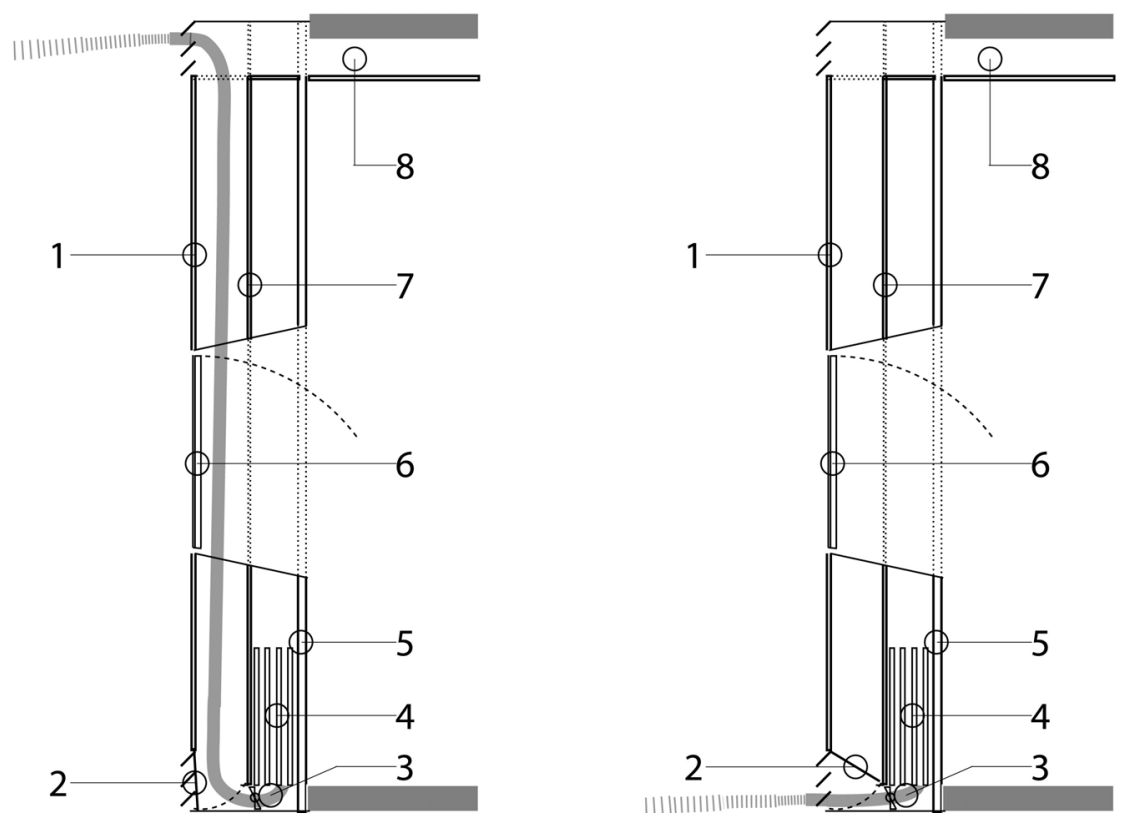

Figure 5: Schematic cross-section of a CAS.

The research it is expected to provide new insights with regard to the functions and functioning of a façade. The design stage, in combination with the production of (a) prototype(s), will deliver a designer's manual which will aid the designer/architect to utilise a new quality in the façade: the ability to react with the changes of the climate, in order to create a comfortable, while energy efficient, indoor environment. 


\section{References}

[1] Davies, M., A Wall for all seasons + Uses for glass in building, Riba Journal-Royal Institute of British Architects, 88 pp. 55-57, 1981

[2] Ree, H.J.v. and Hartjes, Al, Huisvesting in dienst van de medewerker, BOSS Magazine, pp. 4-7, 2003

[3] Winch, G.M., Why should we revalue construction, Revaluing construction 2005: the challenge of change in construction, Rotterdam, 2005.

[4] Raja, L.A., Nicol, J.F., McCartney, K.J. and Humphreys, M.A., Thermal comfort: use of controls in naturally ventilated buildings, Energy and Buildings, 33 pp. 235-244, 2001

[5] Linden, A.C. van der, Boerstra, A.C., Raue, A.K., Kurvers, S.R. and Dear, R.J. de, Adaptive temperature limits: a new guideline in The Netherlands a new approach for the assessment of building performance with respect to thermal indoor climate, Energy and Buildings, 38 pp. 8-17, 2006

[6] Oxford Dictionary, Oxford, 2006

[7] Oesterle, E., Double-skin facades integrated planning, Prestel, München, 2001

[8] Renckens, J., Gevels en architectuur; facades in glas en aluminium, Vereniging Metalen Ramen en Gevelbranche, Nieuwegein, 1996

[9] Wigginton, M. and Harris, J., Intelligent skins, Butterworth-Heinemann, Oxford, 2002

[10] Compagno, A., Intelligente Glasfassaden; Material, Anwendung, Gestaltung, Artemis, Zürich, 1995

[11] Schalkoort, T.A.J. and Luscuere, P.G. Klimaatinstallaties; integratie van gebouw en installaties, TU Delft, Delft, 1996

[12] ISO 8996, Ergonomics of the thermal environment - Determination of metabolic rate, 2004 